\title{
Influence of Residency Training on Personal Stress and Impairment in Family Life: Analysis of Related Factors
}

\author{
A. Ríos ${ }^{a, b}$ F. Sánchez Gascón ${ }^{\text {a, c }}$ J.F. Martínez Lage ${ }^{\text {a,d }}$ M. Guerrero ${ }^{a}$ \\ ${ }^{a}$ Division of Medical Education, ${ }^{b}$ Department of Surgery, ${ }^{c}$ Service of Pulmonology, and \\ ${ }^{\mathrm{d}}$ Neurosurgery, Hospital Universitario Virgen de la Arrixaca, El Palmar, Murcia, Spain
}

\section{Key Words}

Personal stress · Family life · Residency training, satisfaction

\begin{abstract}
Objectives: This cross-sectional study was designed to assess the level of stress among residents and stressrelated impairment of family life. Subjects and Methods: A 41-item anonymous questionnaire was designed to determine the level of stress and its effects on the residents' family as well as factors associated with stress during residency training in a tertiary-care hospital accredited with official resident training 'Medicos Internos Residentes' in Murcia, Spain. Questionnaires were distributed in sealed nominal envelopes during February and March 2002 to 227 eligible residents. Results: Of the 227 residents, 175 (77\%) completed and returned the questionnaires. Forty-two percent of residents recognized that residency training caused an important level of stress and $21 \%$ felt that stress interfered with family relationships. Both factors were significantly associated. Feelings of being unsatisfied with supervision of care and achievement of training objectives as well as low satisfaction with residency training and poor as-
\end{abstract}

sessment of the hospital were significant stressors. Impairment in family life was significantly dependent on degree of satisfaction with residency training and evaluation of the hospital. Conclusion: The data showed that residency training generated stress and impaired family life. These were closely associated with perception of being unsatisfied with the residency training and evaluation.

Copyright (C) 2006 S. Karger AG, Basel

\section{Introduction}

The harmful effects of stress that residents experience during their training have been extensively recognized in the literature [1]. Since 1980, myriad aspects of the stressors and effects of residency training have been discussed in position papers and editorials [2]. Authors have addressed a range of psychological problems, maladaptive reactions and behavior, mood changes, anxiety, depression, and emotional impairment [3, 4]. In a minority of residents with diverse and complex presenting characteristics and underlying issues, debilitating emotional impairment has been associated with prolonged leave of absence, change of career and suicide $[5,6]$.

\section{KARGER}

Fax +4161306 1234 E-Mail karger@karger.ch www.karger.com
Dr. Antonio Ríos-Zambudio Avenida de la Libertad 208 ES-30007 Casillas, Murcia (Spain) Tel. +34 968270 757, Fax +34 968369716 E-Mail arzrios@teleline.es 
Table 1. Specialties included in each trunk group

\begin{tabular}{lll}
\hline Medical services & Surgical services & Central services \\
\hline Allergology & Anesthesiology and Resuscitation & Clinical Analysis \\
Digestive System & General Surgery and the Digestive System & Pathologic Anatomy \\
Cardiology & Cardiovascular Surgery & Clinical Biochemistry \\
Endocrinology and Nutrition & Pediatric Surgery & Hospital Pharmacy \\
Hematology and Hemotherapy & Plastic Surgery and Repair Surgery & Immunology \\
Intensive Care Medicine & Neurosurgery & Nuclear Medicine \\
Internal Medicine & Obstetrics and Gynecology & Preventive Medicine \\
Nephrology & Ophthalmology & Microbiology \\
Pulmonology & Otolaryngology & Clinical Neurophysiology \\
Neurology & Orthopedic Surgery & Radiopharmacy \\
Pediatrics and Specific Areas & Traumatology and Urology & Radiodiagnosis \\
Medical Oncology & & Hospital Radiophysics \\
Psychiatry & & \\
Rheumatology & & \\
Radiotherapy & & \\
Rehabilitation & & \\
\hline
\end{tabular}

Situational, personal, and professional stresses, including time demands, fatigue, sleep deprivation, excessive workload, family conflicts, financial issues, difficult patient problems, information overload, and uncertainty about career opportunities are universally recognized as undesirable stresses of residency training [1]. However, despite recent professionalism and residency reforms [7], an alarming frequency of emotional distress, especially depression, has been well documented [8-12]. The problem of fatigue due to excessively long work hours has been perceived as a possible cause of errors and suboptimal patient care [13]. On the other hand, little is known regarding the effects of residents' distress on friends and family.

Appropriate knowledge of the main causes of high stress levels in residents during training is an essential step towards addressing the principal organizational stressors and to develop primary preventive interventions. In this respect, assessment of the residents' opinions regarding causes and manifestations of stress is an important beginning to identify the scope of the problem. Therefore, a cross-sectional study was conducted with the following objectives: (a) to assess the level of stress among residents in medical training at our institution, (b) to gain more understanding about the effect of stress on residents' physical and emotional health, (c) to determine how stress can affect family relationships and home life, and (d) to identify contributory factors to stress during residency training.

Residency Training: Personal Stress and Impairment in Family Life

\section{Methods}

The study was carried out in a tertiary care hospital accredited with 'Medicos Internos Residentes' (MIR) official resident training in Murcia, Spain. All residents who were on the MIR training in 2002 ( $n=237)$ were surveyed. An anonymous questionnaire was distributed among all residents through the in-house mail service in sealed envelopes during February and March 2002. The questionnaire included sociodemographic data and a total of 41 multiple-choice questions aimed at assessing stress, factors associated with stress, and stress-related impairment in family life during residency training. A discrete continuous scale (from 0 to 10), later grouped into five categories: $0-2,3-4,5-6,7-8$, and 9-10, was used for the assessment of items related to subjective feelings and opinions. The respondents had a choice of five categories for the evaluation of the degree of satisfaction (very unsatisfied: 0-2; unsatisfied: 3-4; normal or indifferent: 5-6; satisfied: 7-8; and very satisfied: 9-10) and the quantification of these items (not at all: 0-2; some 3-4; normal: 5-6; quite a lot: 7-8; and very much: 9-10).

Of the 237 participants in the mailed survey, those who were out of commission (trained for some specialties at another hospital, $\mathrm{n}=10$ ) were excluded. Hence a total of 178 answered questionnaires out of 227 residents participated in the survey, 3 were left blank and were therefore also excluded, thereby resulting in 175 valid surveys. Data analyzed included the following: age, sex, year of residency, trunk group specialty (table 1), achievement of the MIR post desired, satisfaction with the residents' tutor, supervision of care practice, assessment of the service to which the resident was appointed, assessment of achievement of teaching objectives, job expectations after residency training, assessment of rotations during residency training, achievement of objectives of rotations during residency training, assessment of the influence of workload on the resident's training, facilities to be involved in scientific activities, impairment in resident's family life, evaluation of the hospital, and overall degree of satisfaction with their residency training program. 
Table 2. Results of assessment of stress of residency training in 175 valid surveys

\begin{tabular}{|c|c|c|c|c|}
\hline \multirow[t]{2}{*}{ Assessment } & \multicolumn{2}{|c|}{$\begin{array}{l}\text { Stress of residency } \\
\text { training }\end{array}$} & \multicolumn{2}{|c|}{$\begin{array}{l}\text { Impairment of family life } \\
\text { caused by residency training }\end{array}$} \\
\hline & $\mathrm{n}$ & $\%$ & $\mathrm{n}$ & $\%$ \\
\hline Not at all & 30 & 17 & 88 & 50 \\
\hline Some & 26 & 15 & 17 & 10 \\
\hline Normal & 43 & 25 & 30 & 17 \\
\hline Quite a lot & 54 & 31 & 25 & 14 \\
\hline Very much & 19 & 11 & 13 & 7 \\
\hline Nonresponders & 3 & 2 & 2 & 1 \\
\hline
\end{tabular}

Table 3. Relationship between the degree of stress of residency training and impairment in family life

\begin{tabular}{lccccc}
\hline Impairment in family & \multicolumn{4}{l}{ Quantification of the degree of stress } \\
\cline { 2 - 6 } & $\begin{array}{l}\text { not at all } \\
(\mathrm{n}=30)\end{array}$ & $\begin{array}{l}\text { some } \\
(\mathrm{n}=25)\end{array}$ & $\begin{array}{l}\text { normal } \\
(\mathrm{n}=43)\end{array}$ & $\begin{array}{l}\text { quite a lot } \\
(\mathrm{n}=54)\end{array}$ & $\begin{array}{l}\text { very much } \\
(\mathrm{n}=19)\end{array}$ \\
\hline Not at all $(\mathrm{n}=87)$ & $24(80 \%)$ & $13(52 \%)$ & $27(63 \%)$ & $21(39 \%)$ & $2(11 \%)$ \\
Some $(\mathrm{n}=17)$ & $1(3 \%)$ & $2(8 \%)$ & $6(14 \%)$ & $8(15 \%)$ & 0 \\
Normal (n=30) & 0 & $6(24 \%)$ & $7(16 \%)$ & $11(20 \%)$ & $6(32 \%)$ \\
Quite a lot $(\mathrm{n}=24)$ & 0 & $2(8 \%)$ & $3(7 \%)$ & $14(26 \%)$ & $5(26 \%)$ \\
Very much $(\mathrm{n}=13)$ & $5(17 \%)$ & $2(8 \%)$ & 0 & 0 & $6(32 \%)$ \\
\hline \multicolumn{1}{c}{$\mathrm{p}=0.003}$. & & & & \\
\hline
\end{tabular}

Each variable was statistically analyzed in order to detect factors related to stress and impairment in family life. These variables were compared using Student's t test and the chi-squared $\left(\chi^{2}\right)$ test complemented by an analysis of the remainders. Statistical significance was set at $\mathrm{p}<0.05$.

\section{Results}

Of the 175 valid questionnaires analyzed 77 and 98 were from men and women, respectively, with a mean age of $27 \pm 7$ years. With regard to trunk specialties, $47 \%$ of the surveyed residents were in medical specialties, $22 \%$ in surgical specialties, and the remaining in other specialties. In relation to the year of residency training, $22 \%$ were first year, 25\% second year, 26\% third year, 20\% fourth year, and $5 \%$ fifth year. In 4 cases, the year of residency was not completed.

Forty-two percent of residents indicated that residency training caused an important level of stress (very much stress $11 \%$ and quite a lot of stress $31 \%$ ) as shown in table 2 . Stress associated with residency training affected family relationships considerably in $21 \%$ of cases (very much impairment $7 \%$ and quite lot of impairment $14 \%$ ).
There was a statistically significant association between stress and feelings of being unsatisfied with supervision of care practice $(p=0.025)$, achievement of teaching objectives $(p=0.017)$, residency training $(p<0.0001)$, and evaluation of the hospital $(\mathrm{p}=0.001)$. However, stress was not significantly related to the remaining variables.

There was a statistically significant association between impairment in family and not being satisfied with residency training $(\mathrm{p}=0.021)$ and evaluation of the hospital $(p=0.020)$. On the other hand, family relationships were not significantly affected by the rest of the variables. The level of stress and the degree of impairment in family life were significantly associated $(p=0.003$, table 3 ).

\section{Discussion}

Postgraduate training is a stage of life in which adaptation to different stressful situations both at professional and personal levels is necessary for acquiring attributes of maturity [1]. Although it is well known that the medical career is inherently stressful [14], the stress residents experience during their training due to the long hours is 
accentuated by complex interactions of difficulties in balancing time spent in personal and family pursuits, living on relatively low incomes or having to carry heavy debts. Other factors include coping with a highly competitive environment, lack of social support, isolation, problems of relocation and lack of leisure time [1, 2, 6-16]. Family conflicts can exacerbate the work-related stress of residency [15]. Several studies have shown that marriage and/or strong social contacts can have a buffering effect on the stress perceived by physicians in training $[2,17]$.

The identification of sleep deprivation, fatigue, and lack of time for personal interests as major stressors for residents $[1,2,18-20]$ and the growing evidence of the effect of stress on individuals' perceptions of demands and adaptive resources clearly suggested that the time for change in residency training had arrived [2, 3, 21-24]. In 1989, Hoekelman [24] proposed several methods to reduce the stress under which residents worked, in particular, a faculty advisor who offered guidance during training, at least 4 weeks of vacation during each year of training, and limiting the number of consecutive hours and cumulative hours within specified periods of time. Most initiatives for reducing stress during residency have been implemented in nearly all the training programs, but physical and emotional disturbances related to chronic stress are still being reported [8,12,24-26]. After a mailed survey of all 404 internal medicine residency program directors in the USA, Yao and Wright [12] concluded that nearly all programs in this sample had problem residents, in whom the most frequently reported difficulties were insufficient medical knowledge, poor clinical judgment, and inefficient use of time, with stressors and depression as the most frequently identified underlying problems. In a survey of pediatric program directors, Barton and Friedman [25] found that complexity of patient diseases and financial concerns were major stressors for pediatric residents. Finch [26] presented a literature review of pregnancy during residency the results of which supported the need for planning for residents' pregnancies and maternity/parental leave policies. However, despite curricular reforms, Collier et al. [8] examined the financial and emotional situations of internal medicine residents to assess financial status, educational debt, moonlighting, and psychological issues. An alarming number of medicine residents reported depressive symptoms, increasing cynicism, and decreasing humanism; these were associated with increasing educational debt and the need to moonlight for financial survival [8].

In the present study, a high level of stress was reported by $42 \%$ of the 175 residents who participated in the mailed survey. Additionally, $21 \%$ reported that residency training-related stressors impaired family relationships. In our study, like others [1, 2], both circumstances were closely associated and were mainly related to a low degree of satisfaction with residency training and the hospital. This means that physicians' expectations on entering the training program were not met. Despite the fact that $98 \%$ of residents had chosen the specialty they wanted, the level of stress and impairment in family life was high. On the other hand, probably in relation to excessive work demands, additional stressful factors were the feelings of an insufficient supervision of patient care and poor achievement of teaching objectives, which may result in the perception that training received is inadequate. In this respect, ensuring adequate supervision seems a cause of stress more amenable to relief than others. Results of the present study indicate that our residents were more stressed or concerned about qualitative than quantitative aspects of residency training. Although results of this survey cannot be generalized to other hospital settings in different health care systems, our data document that residency training introduces the new physician to some predictable stresses and that for an important percentage of trainees, the level of stress is high and leads to impairment in family life. Personal or emotional problems in response to high levels of stress may prevent the physician from fulfilling professional or personal responsibilities.

It is difficult to specify whether there is a clear direct causal relationship between training-related stress and impairment in family life. However it is clear that there is a close relationship between both, as can be seen in table 3. Therefore, future research directly analyzing these aspects, mainly related to the family, would be useful, because some aspects apart from training stress might determine impairment in family life. Thus, it is probable that this impairment in family life occurs in families with 'small family problems', initially evaluated as not being 'important'. In this family situation, when one of the family members enters the workplace of residency training, with the stress that we have seen it can produce, there could be a breakdown in the family unit. This situation could explain why there is impairment in family life in only a determined group of families with these undetected previous problems. In addition, it is important to know how each person copes with stress, because there are people who cope well and stress does not affect their private life. On the other hand, there are people who cope badly and they carry this stress into their family. The type of family unit is another important factor that could explain the difference in impairment of family life. In this 
sense, some residents are married and with children, others are alone, others have a partner, others live with their parents. All these factors, family-related and personal, need to be studied in greater depth in order to explain in a better way the association between training-related stress and impairment in family life.

Finally, it must be noted that this type of study has limitations, especially depending on the subjectivity with which each individual evaluates stress or satisfaction, which results in two people in the same situation reacting in different ways. However, it is a good tool for detecting these problems and the related factors. Therefore, continued evaluation of residency training programs should be encouraged in order to have timely information and to effectively respond to the unmet needs expressed by trainees under our care.

\section{Conclusion}

Residency training generated stress and impaired family life. These factors were closely associated with perception of being unsatisfied with the residency training and the hospital evaluation. Stress may prevent the physician from fulfilling personal and or professional responsibilities.

\section{Acknowledgment}

Our homage and acknowledgments to Dr. Gómez Rubí (Chief of Division of Medical Education), who recently died. His help, encouragement and spirit have been fundamental for all of us during our residency training.

\section{References}

$\checkmark 1$ Resident Services Committee, Association of Program Directors in Internal Medicine: Stress and impairment during residency training: strategies for reduction, identification, and management. Ann Intern Med 1988;109:154161.

2 Butterfield PS: The stress of residency: a review of the literature. Arch Intern Med 1988;148: 1428-1435.

-3 Colford JM Jr, McPhee SJ: The ravelled sleeve of care: managing the stresses of residency training. JAMA 1989;261:889-893.

4 Ford CV: Emotional distress in internship and residency: a questionnaire study. Psychiatr Med 1983;1:143-150.

5 Smith JW, Denny WF, Witzke DB: Emotional impairment in internal medicine house staff: results of a national survey. JAMA 1986;255: 1155-1158.

6 Kirsling RA, Kochar MS: Suicide and the stress of residency training: a case report and review of the literature. Psychol Rep 1989;64: 951-959.

7 Reynolds PP: Professionalism and residency reform. Bull N Y Acad Med 1991;67:369-377.

$\checkmark 8$ Collier VU, McCue JD, Markus A, Smith L: Stress in medical residency: status quo after a decade of reform? Ann Intern Med 2002;136: 384-390.
-9 Shanafelt TD, Bradley KA, Wipf JE, Back AL: Burnout and self-reported patient care in an internal medicine residency program. Ann Intern Med 2002;136:358-367.

10 Ríos A, Sánchez Gascón F, González L, Guerrero M: Factores de insatisfacción de los médicos internos residentes. Med Clin (Barc) 2003; 121:634-635.

11 Schneider KM, Monga M, Kerrigan AJ: Stress in residency: reality or myth? Am J Obstet Gynecol 2002;186:907-909.

12 Yao DC, Wright SM: National survey of internal medicine residency program directors regarding problem residents. JAMA 2000;284: 1099-1104.

13 Firth-Cozens J: Doctors, their wellbeing, and their stress. BMJ 2003;326:670-671.

14 Mumford E: Stress in the medical career. J Med Educ 1983;58:436-437.

15 Landau C, Hall S, Wartman SA, Macko MB: Stress in social and family relationships during the medical residency. J Med Educ 1986;61: 654-660.

16 Levey RE: Sources of stress for residents and recommendations for programs to assist them. Acad Med 2001;76:142-150.

17 Rudner HL: Stress and coping mechanisms in a group of family practice residents. $\mathrm{J}$ Med Educ 1985;60:564-566.
18 Asken MJ, Raham DC: Resident performance and sleep deprivation: a review. J Med Educ 1983;58:382-388.

19 Whitley TW, Gallery ME, Allison EJ Jr, Revicki DA: Factors associated with stress among emergency medicine residents. Ann Emerg Med 1989;18:1157-1161.

20 Young EH: Relationship of residents' emotional problems, coping behaviors, and gender. J Med Educ 1987;62:642-650.

21 Weiner PS: A social-discussion group for firstyear residents. J Med Educ 1984;59:137-139.

22 Brashear DB: Support groups and other supportive efforts in residency programs. J Med Educ 1987;62:418-424.

23 Matthews DA, Classen DC, Willms JL, Cotton JP: A program to help interns cope with stresses in an internal medicine residency. J Med Educ 1988;63:539-547.

24 Hoekelman RA: Stress experienced during pediatric residency training: its causes, consequences, recognition, and solutions. Am J Dis Child 1989;143:177-180.

25 Barton LL, Friedman AD: Stress and the residency program director. Arch Pediatr Adolesc

Med 1994;148:101-103.
26 Finch SJ: Pregnancy during residency: a literature review. Acad Med 2003;78:418-428. 